\title{
A Structural Language for a Conceptual Design Collaboration
}

\author{
L. Luyten \\ Associated Faculty of Architecture at KU Leuven, Campus Sint-Lucas, Brussels, Belgium
}

\begin{abstract}
: this paper presents a proposal for a new structural language and its evaluation in educational practice. The proposed language is developed as a communication and design tool for a structurally informed design collaboration between architect and structural engineer that starts early in the design process. In various case studies architecture students express their appreciation for the proposed language not only for its application in design collaborations but also in providing a structural understanding adapted to their architectural design culture.
\end{abstract}

\section{A STRUCTURAL LANGUAGE FOR CONCEPTUAL DESIGN}

\subsection{Design collaboration during a conceptual design phase}

When developing design solutions, architects tend to look for a variety of possible design answers before going in depth into one array of solutions. According to Ömer Akin, architects use a hybrid search strategy of breadth-first followed by depth-first in answering an architectural design question (Akin 2001). In other words, architects tend to spend much attention in investigating different design concepts and conceptual designs before choosing one to develop in further detail. This strategy enables architects to explore a wide variety of design solutions.

When exploring design possibilities it is important to be well-informed of the various consequences of possible design choices. Since each architectural form requires an adapted structure, creating architectural form will influence structural design, and in return a creation of structural form can importantly affect architectural design. As architectural form creation often starts in the early stages of design, an appropriate collaboration in these early stages is required for both architect and structural engineer - as designer of structural form - to be well-informed of each other's design process.

Such a collaboration during conceptual design asks for an adapted communication, in which for example well-informed design decisions are still conveyed even if ill-informed ones are delayed until the required information is gathered. (Often design decisions are taken based on sometimes wrongly - assumed information in order to establish a communication of detailed design propositions). A delay decision strategy (i.e. to delay design decision until sufficient information is gathered) enables to retain an in breadth-first search strategy for design solutions, avoiding an inconsiderate narrowing down of design possibilities (Lottaz et al. 2000; Stouffs 2000). The communication of conceptual design propositions of an early design collaboration, requires to express a wide range of possible design solutions in which common characteristics are brought to the fore that reveal already made design decisions and in which ill-informed design decisions can still be left open. 


\subsection{Need for a structural language for conceptual design propositions}

Structural design propositions described with currently available engineering languages are in general closely related to calculation methods which only require a few additional design decisions to come to a design solution. 'In general, engineers tend to categorise structures according to which mathematical model and technique of structural analysis they might use, ...' (Addis 1994, p.12). This leads to building blocks for a design creation of various structural typologies like beam, column, slab, tie, Vierendeel-girder, truss-girder, dome shell and peak tent. Each of these typologies possesses distinctive characteristics of structural analysis and are accompanied by methods of dimension calculations. These structural building blocks of design contain already many design decisions and hinder a more conceptual design creation of structures.

Therefore within the doctoral work of the author (Luyten 2012), a proposal for a new structural language to describe very conceptual design propositions is developed through participatory action research in various cases of his professional and academic practice. This proposed language is away from commonly used structural typologies and their calculation methods, is in addition to currently available structural languages, and enables to express essential characteristics of a structural design proposition pertaining to early design decisions of a structural engineer.

\section{STRUCTURAL LANGUAGE PROPOSAL}

\subsection{A language of four layers}

The proposed structural language expresses structural logic through an abstract representation with symbols that finds meaning in four different layers: (1) structural order, (2) structural function, (3) structural dimensions and (4) structural design possibilities.

(1) Structural order reveals the structural relations between different structural elements for a specific load case: it shows which element is supported by which other element(s). It brings to the fore the path(s) a load follows throughout the system of structural elements to its supports (Figure 1).

The layer of (2) structural function expresses the type of load transfer that occurs in a structural element: axial or parallel transfer of force, or axial or parallel transfer of moment. Each structural element is required to perform its structural function(s) to enable the structural system to bring the load to the supports.

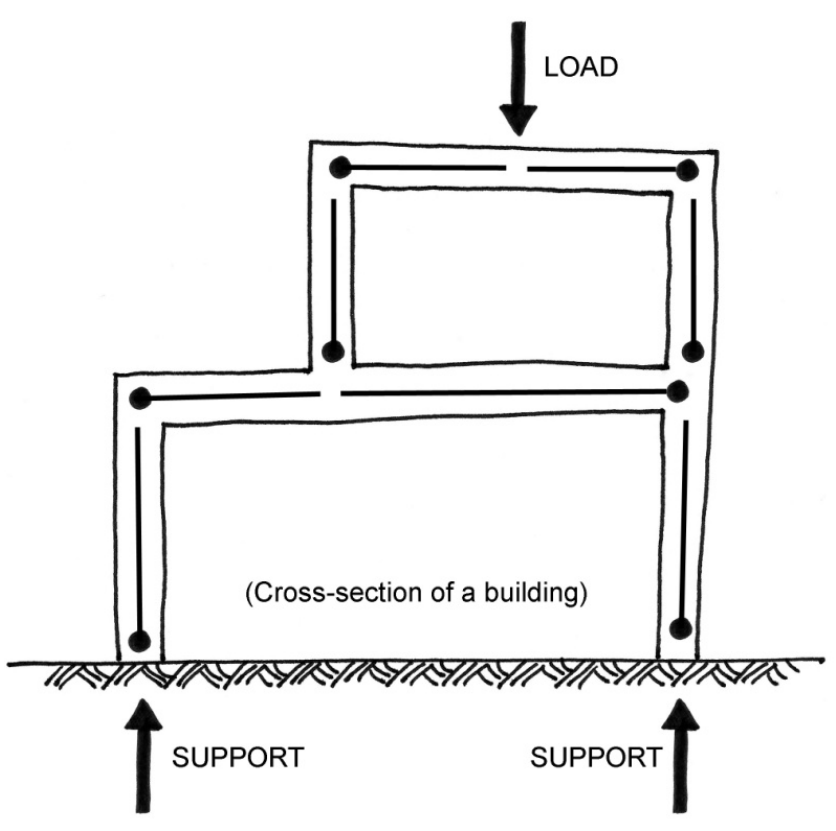

Figure 1. Example of structural order: identification of structural axis (-) and load paths (•) 


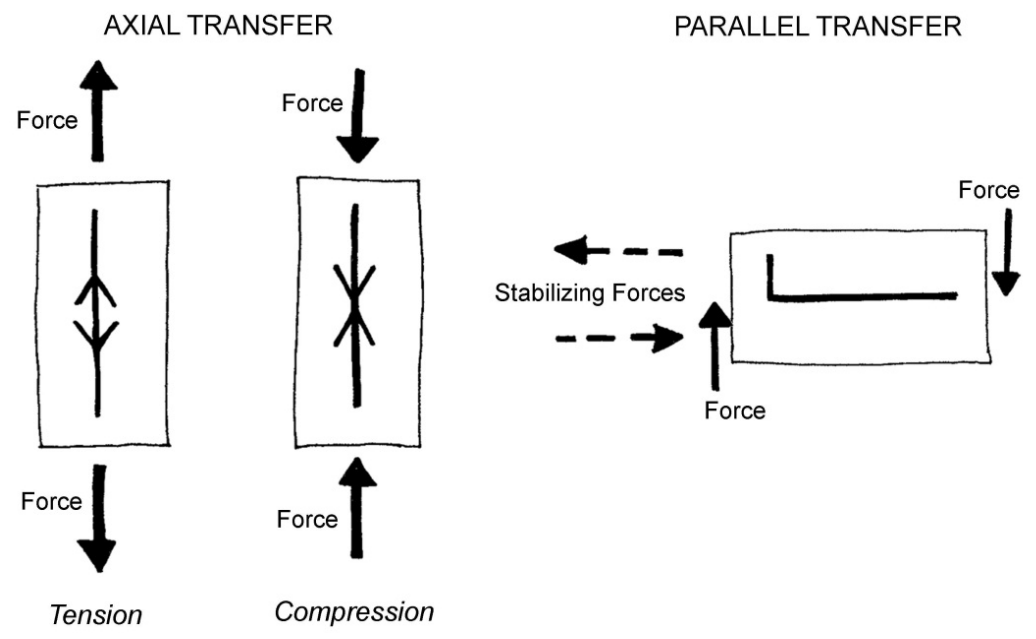

Figure 2. Structural dimensions layer: symbols for transfer of force.

The consequences of performing a structural function on the structural form of an element are expressed in the layer of (3) structural dimensions. This leads to five major types of structural dimensions: one for each type of structural function except axial transfer of force which is split into tension and compression (since buckling needs to be additionally considered for dimensioning in the latter). This means that expressing the characteristics of structural dimensions also reveals the underlying characteristics of structural functions that each element needs to perform (Figure 2).

The layer of (4) structural design possibilities links each element and its characteristics of structural dimensions with a wide range of possible (built) structural design solutions. These solutions as material form bring the conceptual design into the realm of built reality of structures - and also of architecture as each material form contains architectural qualities.

The proposed language consists of symbols that express characteristics of the layers structural order and dimensions, and is accompanied with a catalogue of (built) structural design solutions organized according to their characteristic of structural dimension and architectural expression of conceptual form.

\subsection{Qualities of the proposed language}

In the proposed language for expressing conceptual structural design propositions, various qualities can be identified:

- communicate structural logic (by expressing the characteristics of the layers structural order and structural dimensions).

- articulate conceptual design decisions of the engineer for negotiation (i.e. mainly the identification of the chosen structural elements, loads, supports, load paths, required function(s) of each structural element and the type of element connection).

- provide for more abstract building blocks of design creation (i.e. more conceptual than common structural typologies) and even structural prototypes (i.e. a fully formed but profoundly abstract answer to a design question; Figure 3).

- enable a delay decision strategy (i.e. to express structural logic of a design proposition without the need for more detailed information of structural typologies, material or dimensions).

- filter structural information for the architect (i.e. reduce the amount of engineering-specific knowledge required to understand structural logic, and focus information on decisive characteristics of structural dimensions).

- easily and quickly drawn, and intuitively understandable.

- organize structural knowledge through a process of design refinement (i.e. going from conceptual principles to detailed design solutions).

- allow a personalized expression of structural design (i.e. contain poetic freedom in use for a personal expression of structural phenomena). 


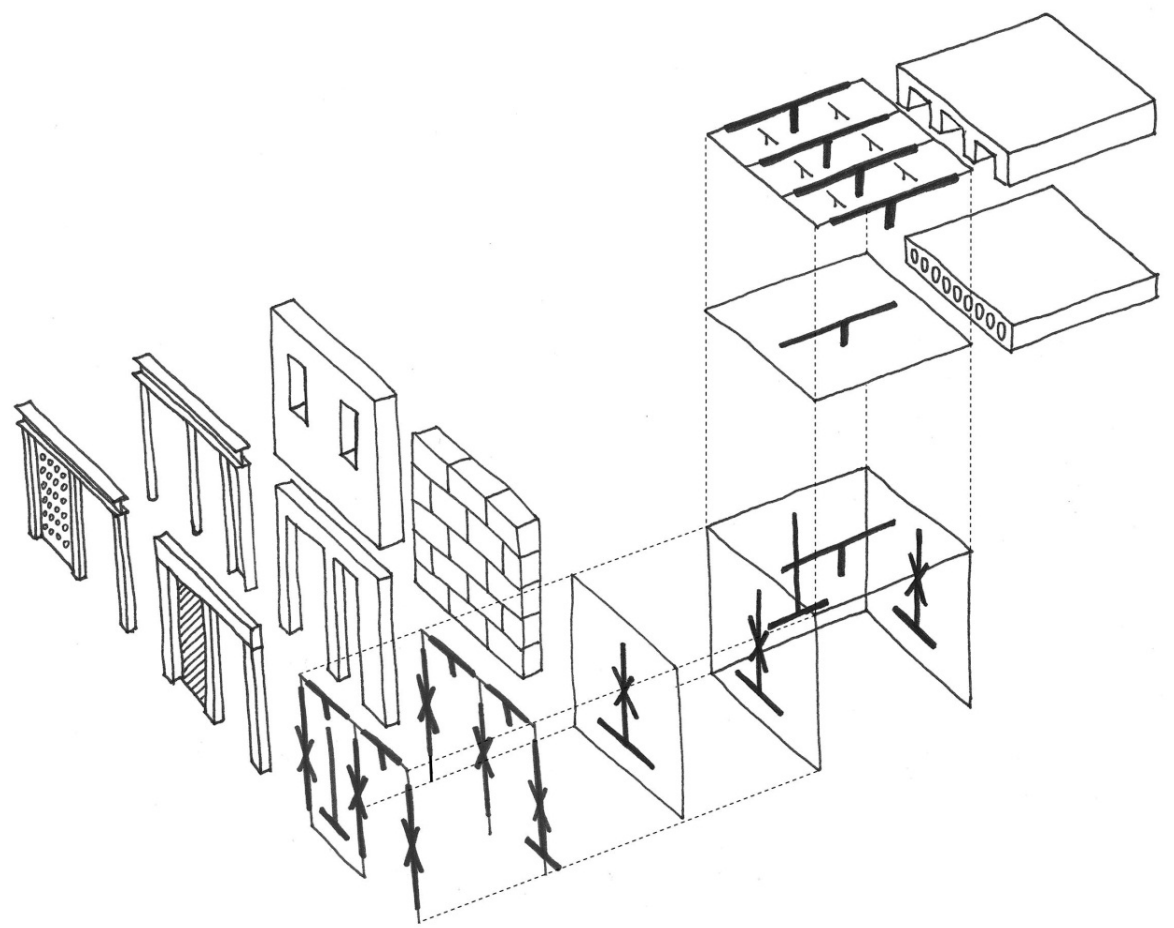

Figure 3. Example of structural prototype: from prototype to a range of possible design solutions.

\subsection{Language application}

During an informed collaboration between architect and structural engineer, the proposed language of symbols can be applied to an architectural form model by providing each conceptual element with structural information about its structural order and dimensions. This means that a structural element is represented according to its architectural expression of form, and structurally informed with the new language. This can lead to rich three-dimensional drawings that on the one hand express the structural behaviour of a system of conceptual elements, and on the other hand create spatial experiences that relate directly to architectural design (Figure 4). Such drawings then provide a common ground for communication during design collaboration between architect and structural engineer.
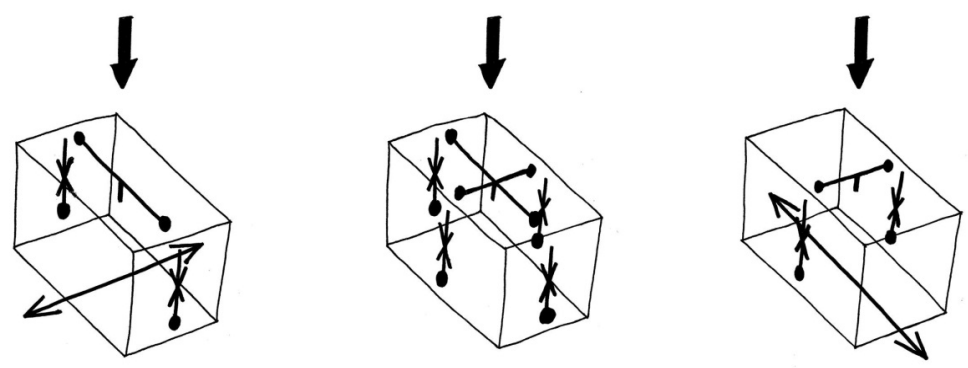

Figure 4. Articulation of conceptual design decisions: choice of structural elements, their functions and connection, load path and supports.

The proposed language is developed (1) for architects and architecture students to easily learn, read and apply it, and (2) as a communication tool in face-to-face meetings of structurally informed architectural design collaborations that start early in a design process. The language is also (3) applicable in structural design to create proposition drawings (Lawson 2005, pp.45-49) of conceptual structural design propositions in order to stand back and 'have a conversation' with the own developed conceptual design. Through the language's ability to provide rich three-dimensional drawings, it (4) facilitates a three-dimensional investigation of structural de- 
sign in which the third dimension might reveal more creative design possibilities than would an investigation relying on two-dimensional drawings. The proposed language can also (5) play an important part in structural education, as it requires a minimum understanding of engineering knowledge to explain how a structure functions, and because it starts out from an understanding of basic structural concepts before going into detailed analysis and calculations (which is in contrast to common structural education in engineering sciences).

\section{CASE STUDIES}

Different cases have been staged with architecture and interior architecture students in the educational practice of the author. These case are used to evaluate the proposed structural language in an individual application by the students and in design collaborations between students and the author as structural engineer.

\subsection{Evaluation of language in an individual application of architecture students}

Two seminar are used for an extensive evaluation of the students' appreciation for the language to express structural behaviour. Seventy-eight architecture and interior architecture students in the last two years of their educational program participated in these evaluations. All involved students have passed their structural education program, which includes a learning of traditional engineering languages. Students are asked to structurally investigate an object of their choice and express that understanding in a presentation through their own chosen language. After handing in their presentations, the newly developed structural language is introduced to the students in a short time span of one hour and a half (Figure 5). The students are then asked to express the same structural understanding of their object with this new language in a new presentation (Figure 6). The qualities of the proposed language are evaluated by a comparison by the author of both students' presentations of the same structural story, and through extensive and well-prepared questionnaires that investigates the students' opinions.

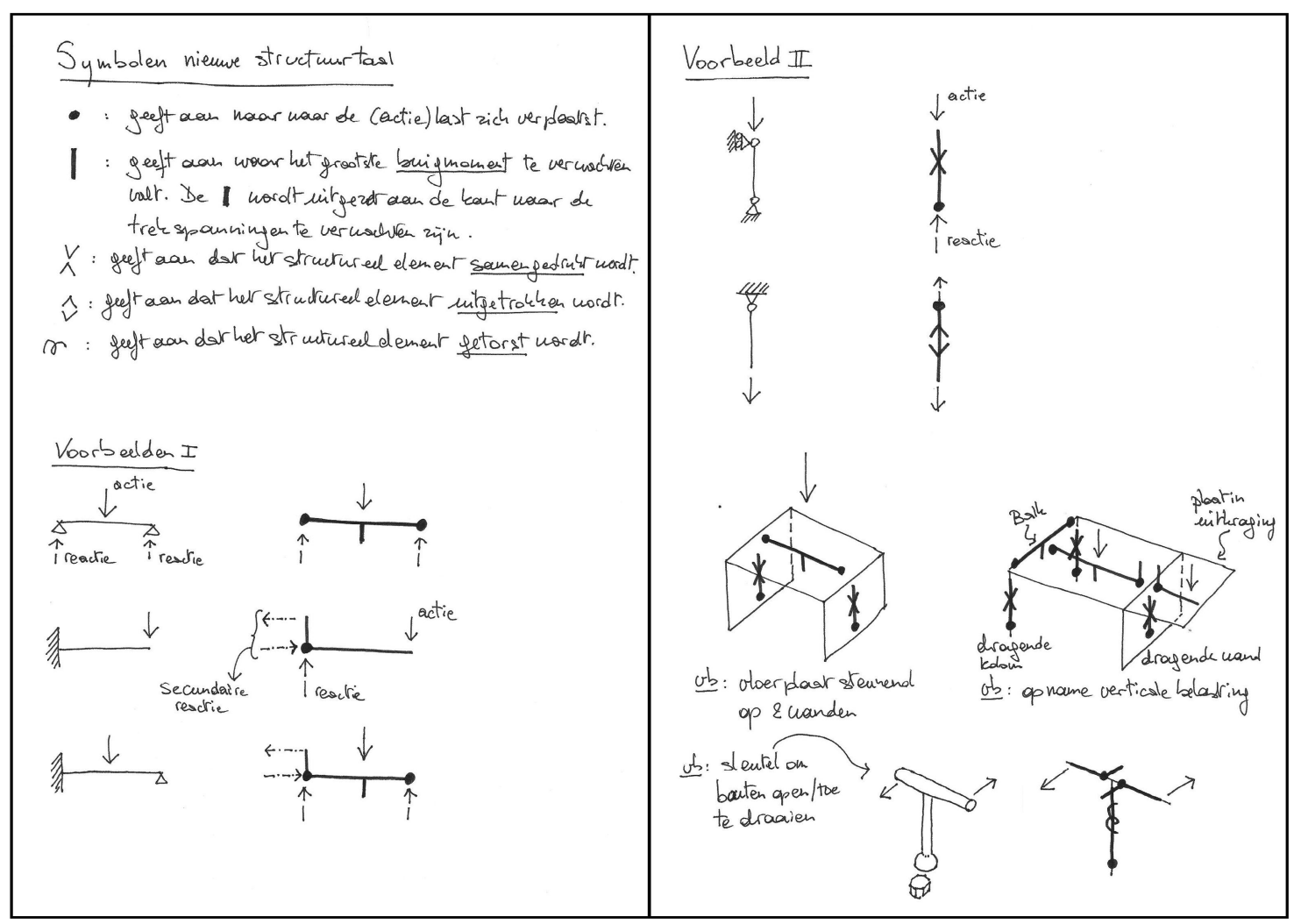

Figure 5. Short manual of the new structural language provided to the students. 

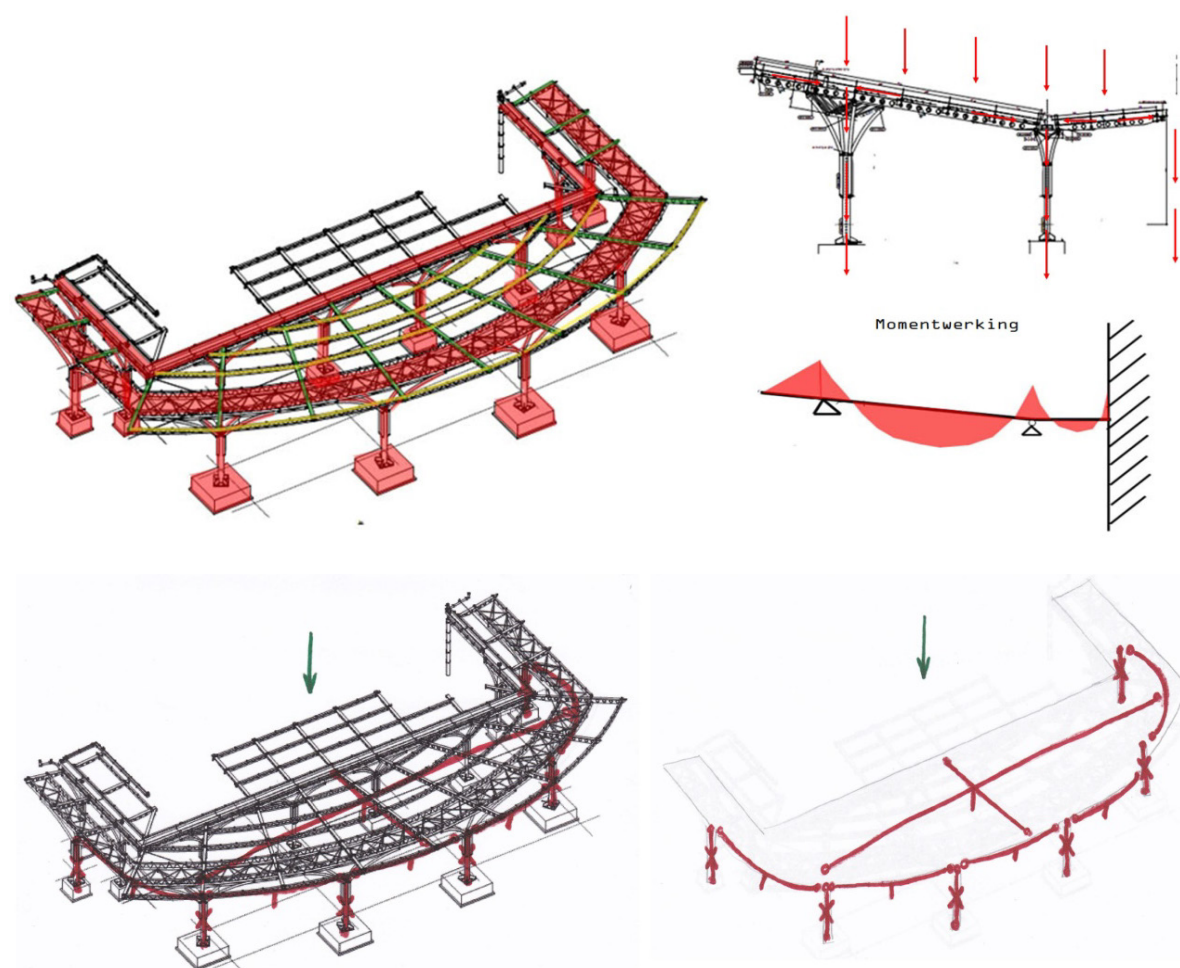

Figure 6. Student's example of similar structural story with traditional (top) and new (bottom) languages.

The questionnaires reveal that the students found (1) the new structural language easy to learn and use; the proposed symbols of the language are clear and intuitively understandable. (2) $90 \%$ of the students found that the essence of structural behaviour as they comprehend it could be explained well with the new language. (3) $81 \%$ of the students feel they can tell more about the structure in one image using the new structural language than with their usual language.

Comparing both presentations of the same structural story reveals that (4) when the structural behaviour is well understood by the students, both structural narrations are often almost equal, although the narration with the new language does not require as many images. In most cases, the students are capable of using the language correctly.

In the next part of these seminars, students are asked to alter their self-developed structural form model of the investigated object while keeping track of the consequences on the structural behaviour of these alterations. This exercise obliges them to design structurally. In this exercise they were not bound to use the new language.

New questionnaires are presented to the students that reveal that (5) about half of the students feel that their general structural knowledge is increased by the use of this language, and that (6) if other people understood these symbols, $75 \%$ of the students would prefer using these symbols above the traditional internal forces diagrams to explain a structure. The questionnaires also show that (7) $85 \%$ of the students find it an asset to be able to use this language for this variation design exercise: they appreciate not having to go into designing details and being able to work only with a more abstract conceptual structure. (8) About $70 \%$ of the students voluntarily used the new language during their design process in this exercise. (9) $40 \%$ of the students that used the language during their design process express to have found new structural design ideas at some point through the use of this new language.

\subsection{Evaluation of language in design collaborations of architecture students and engineer}

In order to investigate the use of the new language as a communication and design tool in a design collaboration, a seminar is staged. In this seminar six design collaborations are established in a design studio setting between on the one hand six architecture students and one interior design student, all in their master years, and on the other hand the author as structural engineer. These collaborations occur in face-to-face meetings spread over several weeks, and 
involve the participation of an additional tutor taking care of the architectural qualities of the various design projects. The collaborations are set early in the design process and intend to structurally inform architectural design. The communication of structural design occurs through the use of the new structural language during the face-to-face meetings (Figure 7). The students are asked to keep a log of their design process, especially before and after a face-to-face meeting in order to make them aware of their own design process evolution and its relation to the received structural information.

After handing in their design projects, students fill in a questionnaire with open-ended questions about the face-to-face meetings and the use of the language. Together with a follow-up discussion with all students on their appreciation of the design studio in general and the use of the structural language in particular, the following can be concluded:

- Students describe the structural language used in the face-to-face meetings as clear, direct, pure, intuitive, understandable and quick: you can learn it by using it; it does not need much explanation.

- Students state that the language is useful for the first phase of the design process, when there is a need for more abstract structural ideas, but that something 'more' is needed later on in the design process, when there is a need for more detailed information that this language does not provide.

- There is a limit on the amount of understandable information that can be put in one drawing. Thus in case of complex structures or too many load cases, more than one three-dimensional view is needed, or more (two-dimensional) drawings need to be made.

- The language provides structural information on the level of an architect's design culture. Students value the visual communication (with the language) more than a spoken one.

- Students say they use the language in their mind without putting it on paper, and that through the use of simple wire-frame models for the structural form models they are able to manipulate the conceptual design in their mind.

- Some students say they find it essential to limit the number of different symbols in the language in order to gain more insight into the structural essence.

- Students look forward to using a catalogue that links the conceptual design (expressed in the language) with the variety of built reality for their architectural design process.

- Students would like to see this language applied in and linked with present theory courses.

- Students say they have let the structural input guide their design process.

- One student says she uses the language in other design studios now, and even with student colleagues who are not familiar with the language. She says these other students find the language easily to learn.

In addition, based upon his notes and the produced project results of the students, the author concludes that (1) the language enables him to quickly and easily write down the structural story of a conceptual design proposal, with the advantage to be (2) still consultable by students after the meeting is over. (3) The students are able to grasp the expressed structural behaviour of the structural proposition and if necessary change the presented structural form model within sound structural logic: the new language provides sufficient information to understand the expressed structural behaviour. The evolution and results of the different design processes also make apparent that (4) the architectural design process is guided by the given structural information, and thus that the architectural design gets structurally informed through the use of the new language. 

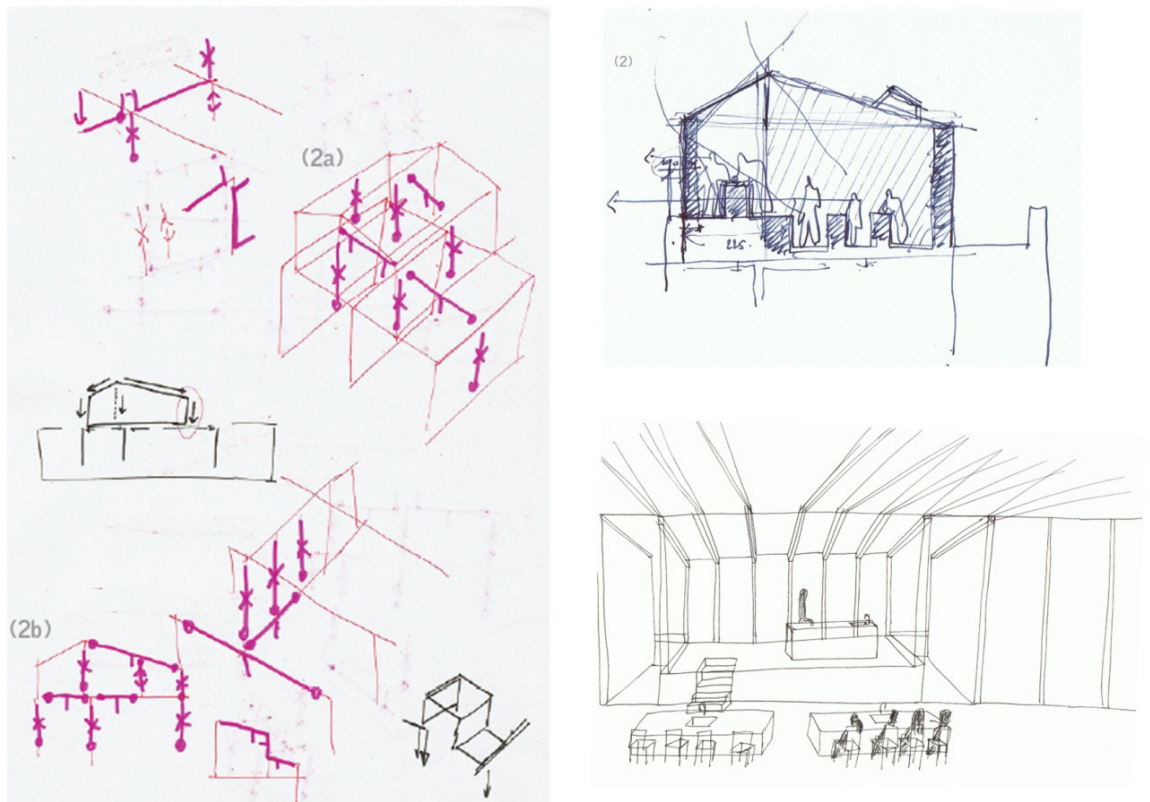

Figure 7. Example of student's design project: conceptual structural design sketch and architectural proposition before (top) and after (bottom) structural consultation.

\section{CONCLUSIONS}

The proposed structural language consists of symbols to express structural order, function and dimensions, and contains a built-in relation between structural conceptual design elements and (built) design solutions. The various case studies show that for most (interior) architecture students the language is easy to learn and use. The results of the variation exercise and the students' responses show that the language helps an important number of students to conceptually design structures. The nature of the language and the conceptual design paradigm for which it stands, seem to be closely related to the student's architectural design paradigm, as most of them voluntarily choose to use this language during their design process. The proposed language is well received with the (interior) architecture students as communication and design tool during the conceptual design phase of a collaboration with a structural engineer that starts early in the design process. During later phases of design a more detailed and accurate information exchange is required which current available structural languages can provide for.

\section{REFERENCES}

Addis, B. 1994. The Art of the Structural Engineer. London: Artermis London.

Akin, Ö. 2001. Variants in design cognition. In C. Eastman, M. McCracken, \& W. Newstetter (eds), Design Knowing and Learning Cognition in Design Education.:105-124. Oxford: Elsevier.

Lawson, B. 2005. How designers think: the design process demystified 4th ed. Oxford: Architectural Press.

Lottaz, C., Stouffs, R. \& Smith, I. 2000. Increasing Understanding During Collaboration Through Advanced Representations. Journal of Information Technology in Construction 5: 1-24.

Luyten, L. 2012. Structurally Informed Architectural Design, Proposals for a Creative Collaboration between Architect and Structural Engineer. Ph. D. Göteborg: Chalmers University.

Stouffs, R. 2000. Resolving issues of information and communication in a building project. itc.scix.net. Available at: http://itc.scix.net/cgi-bin/works/Show?w78-2000-895 [Accessed May 24, 2012].

Research website: http://engineeringarchitecture.wikispaces.com 